\title{
EVALUATION OF A SUMMER BIOCHEMISTRY COURSE SETTLED BY GRADUATE STUDENTS (PMBqBM/SBBq) AIMING UNDERGRADUATE STUDENTS
}

\author{
Pompeu, D.G. ${ }^{1}$; Gonçalves, D.B. ${ }^{1}$; Ribeiro, R.I.M.A. ${ }^{1}$; Granjeiro, P.A. ${ }^{1}$ \\ ${ }^{1}$ Campus Centro-Oeste, Universidade Federal de São João del Rei, Divinópolis, Minas \\ Gerais, Brazil
}

The good development of research in biochemistry is strongly linked to the knowledge and skill of the professional in using the techniques available to perform the research. To do this, the researcher must have adequate training and the period of initiation to science during graduation is of fundamental importance for the formation of this professional. Graduate students, in its turn, must seek to strengthen their knowledge and development of their teaching skills. In this scenario, the Multicenter Postgraduate Program in Biochemistry and Molecular Biology (PMBqBM) - (Brazilian Society for Biochemistry and Molecular Biology - SBBq - and Federal University of São João del Rei, Campus Midwest - UFSJ/CCO) joined the Postgraduate Program in Biotechnology (UFSJ/CCO) for the creation of I Summer Course in Biochemistry, Molecular Biology and Biotechnology of UFSJ. The objective was to promote the dissemination of the research areas in biochemistry present in UFSJ as well as both Postgraduate programs. This course was organized and taught by students of the two Postgraduate programs and exclusively aimed to undergraduate students from other institutions. In it, undergraduate students could choose from 12 courses of different lines of research linked to the areas of Biochemistry, Molecular Biology and Biotechnology established at UFSJ. The course, lasting 40 hours, had 80 subscribers for a total of 61 vacancies. Registrants were from 8 different Brazilian states and 12 different graduate degree courses, especially Biology. The course had average rating of 9.4 , and the practical activities reached the rate of $100 \%$ positive evaluations. Through the observation of results obtained, it is concluded that the course met its main objectives to strengthen ties between institutions where develop research in biochemistry, to promote teaching and training techniques, as well as disclose the Postgraduate courses on Biochemistry, especially PMBqBM.

Keywords: Biochemistry, education, SBBq 